\title{
BMJ Global Health Assessing the impact of polio supplementary immunisation activities on routine immunisation and health systems: a systematic review
}

Amy Vassallo (D , , ${ }^{1,2}$ Kimberly Dunbar, ${ }^{3}$ Busayo Ajuwon, ${ }^{3}$ Christopher Lowbridge, ${ }^{4}$ Martyn Kirk, ${ }^{3}$ Catherine King, ${ }^{5,6}$ Meru Sheel (i) ${ }^{3}$

To cite: Vassallo A, Dunbar K, Ajuwon $B$, et al. Assessing the impact of polio supplementary immunisation activities on routine immunisation and health systems: a systematic review. BMJ Global Health 2021;6:e006568. doi:10.1136/ bmjgh-2021-006568

Handling editor Seye Abimbola

Received 9 June 2021 Accepted 12 October 2021

Check for updates

(c) Author(s) (or their employer(s)) 2021. Re-use permitted under CC BY-NC. No commercial re-use. See rights and permissions. Published by BMJ

For numbered affiliations see end of article.

Correspondence to

Dr Meru Sheel;

meru.sheel@anu.edu.au

\section{ABSTRACT}

Introduction The Global Polio Eradication Initiative uses polio supplementary immunisation activities (SIAs) as a strategy to increase vaccine coverage and cease poliovirus transmission. Impact of polio SIAs on immunisation systems is frequently debated. We reviewed the impact of polio SIAs on routine immunisation and health systems during the modern era of polio eradication.

Methods We searched nine databases for studies reporting on polio SIAs and immunisation coverage, financial investment, workforce and health services delivery. We conducted a narrative synthesis of evidence. Records prior to 1994, animal, modelling or case studies data were excluded.

Results 20/1637 unique records were included. Data on vaccine coverage were included in $70 \%(14 / 20)$ studies, workforce in 65\% (13/20) and health services delivery in $85 \%$ (17/20). SIAs positively contributed to vaccination uptake of non-polio vaccines in seven studies, neutral in three and negative in one. Some polio SIAs contributed to workforce strengthening through training and capacity building. Polio SIAs were accompanied with increased social mobilisation and community awareness building confidence in vaccination programmes. Included studies were programmatic in nature and contained variable data, thus could not be justly critically appraised.

Conclusion Polio SIAs are successful at increasing polio vaccine coverage, but the resources and infrastructures were not always utilised for delivery of non-polio vaccines and integration into routine service delivery. We found a gap in standardised tools to evaluate SIAs, which can then inform service integration. Our study provides data to inform SIAs evaluations, and provides important considerations for COVID-19 vaccine roll-out to strengthen health systems.

PROSPERO registration number CRD42020152195.

\section{INTRODUCTION}

In 1988, the World Health Assembly resolved to eradicate polio globally by 2000 . Consequently, the Global Polio Eradication Initiative (GPEI) was launched as one of the largest ever public health initiatives with a goal to

\begin{abstract}
WHAT IS ALREADY KNOWN?
$\Rightarrow$ Previous analyses of the impact of polio eradication activities on routine immunisation and health systems have shown mixed results.

WHAT ARE THE NEW FINDINGS?

$\Rightarrow$ This systematic review revealed that positive impacts of polio supplementary immunisation activities (SIAs) delivered as part of eradication activities can occur if there is adequate staffing and infrastructure, especially increased access to services particularly in difficult-to-access areas and improvements in surveillance systems.

$\Rightarrow$ In contrast, disruptions to routine health services were reported in some studies, particularly when additional human resources were not incorporated to deliver SIA and existing staff were redeployed.

\section{WHAT DO THE NEW FINDINGS IMPLY?}

$\Rightarrow$ SIAs have mixed impacts on immunisation coverage and systems.

$\Rightarrow$ Polio SIAs include missed opportunities that could be used to strengthen health systems, workforce and infrastructure. Lessons learnt should be considered in the context of COVID-19 vaccine roll-out over the coming years.

$\Rightarrow$ Systematic review methodologies and quality assessment tools require reform to be suitable for assessments and synthesis of programmatic research and interventions, particularly in low-income and middle-income country settings.
\end{abstract}

immunise every child against polio and eradicate the disease. ${ }^{1}$ To date, the original global eradication goal targets have not been met, however, substantial progress has been made, with the eradication of two of the three wild poliovirus (WPV) serotypes (types 2 and 3). ${ }^{23}$ In 1994, the Americas region of WHO was the first to formally achieve polio elimination. ${ }^{4}$ In addition, outbreaks due to circulating vaccine derived poliovirus (cVDPV) also continue to occur, with 54 transmission 
emergencies between January 2018 and March 2020, requiring ongoing response under the GPEI. ${ }^{2}$

The GPEI adopted a multipronged approach to polio elimination efforts: increasing immunisation coverage by conducting supplementary immunisation activities (SIAs), enhancing surveillance of acute flaccid paralysis and establishing a sustainable mechanism for house-tohouse mop-up campaigns. ${ }^{5}$ SIAs are known as mass vaccination campaigns or national immunisation days and involve the mass vaccination of all children in a specific age group, regardless of their previous immunisation status. SIAs aim to interrupt circulation of poliovirus by capturing children who have not already been vaccinated through routine immunisations and boost immunity of those children who have been immunised. They occur periodically in multiple rounds. ${ }^{6}$ Over the last two decades, polio SIAs were used to deliver an estimated 10 billion doses of polio vaccine to children across the globe, ${ }^{7}$ and have succeeded in interrupting virus transmission in most, but not all, countries. While SIAs have been effective at increasing coverage of polio vaccine, their impact on immunisation for other antigens under Expanded Programme on Immunisation (EPI) and health systems have been frequently debated in the literature and by public health practitioners. ${ }^{8-10}$

Previous examination of polio eradication activities in several countries and their effects on routine immunisation and health systems have provided mixed results. ${ }^{11-13}$ A multicountry study showed that polio campaigns enhanced the delivery of other child interventions, including vitamin A supplementation and deworming medicines among other benefits. ${ }^{14}$ In particular, polio SIAs were used as a medium to distribute insecticidetreated bed nets in malaria endemic countries. ${ }^{15}$ Similarly, studies in Cote d'Ivoire, Ghana, India and Nepal conducted between 1990 and 2001 showed that the implementation of polio eradication activities through national immunisation days improved access and completion rates of polio and non-polio vaccines. ${ }^{12}$

A study from the Western Pacific Region found polio SIAs introduced as part of regional polio eradication efforts (1991-1995) helped with increasing coverage for routine immunisation in countries with below average coverage. For example, in Cambodia and the Lao People's Democratic Republic, the countries with the lowest immunisation rates in the Western Pacific Region in 1990, polio immunisation coverage increased by $>30 \%$ and $100 \%$, respectively, during 1991-1995 period. Among the remaining countries (China, the Philippines and Vietnam), coverage for BCG, DTP3 and measles vaccine remained at $\geq 85 \%$ during the same period. SIAs were also noted to increase public awareness of routine services. ${ }^{16}$ Another study investigating cost-effectiveness of SIA models for polio and measles in South Africa advocated for a health systems approach for delivering interventions, as cost-effectiveness of SIA delivery substantially increased when combined with other interventions. ${ }^{17}$ Despite demonstrations of positive impacts, a previous literature review published in 1997 highlighted that little information was available on whether SIAs strengthen routine services, or offer untapped potential for strengthening routine immunisation systems. ${ }^{18}$ To our knowledge, no systematic reviews with contemporary evidence during the modern era of polio eradication exist.

In this review, we systematically examined how polio SIAs impacted routine immunisation and elements of health systems, including financial investment, human resources including workforce strengthening and health services delivery. This is of particular relevance and timeliness, given that the latest GPEI Strategy for the period 2022-2026 includes an increased focus on integration between polio eradication and partners, essential health services and community services, including supporting activities such as COVID-19 vaccine distribution. ${ }^{19}$ With disruption to routine immunisation programmes due to COVID-19 in many countries, and with ongoing transmission of WPV and cVDPV, enhanced efforts and systems thinking is required to continue and re-enforce polio eradication efforts and prevent resurgence. ${ }^{2021}$ For example, in Pakistan, a country with ongoing polio virus transmission and weaker health systems where SIAs are important interventions for increasing polio immunisation coverage, two studies reported $\sim 50 \%$ reduction in routine immunisation coverage in May 2020.22 23 These reductions can be attributed to several factors including disruption of routine health services, reallocation of staff to COVID-19 response and inability of the community to access health services due to lockdowns and fear of contracting COVID-19. While many routine immunisation systems were restored by early 2021, the ongoing nature of the COVID-19 pandemic continues to threaten routine immunisation including polio globally. There is greater need to examine mass vaccination campaigns and design approaches based on lessons learnt to better manage and bolster response to epidemic-prone diseases that are also vaccine preventable such as polio, measles and COVID-19.

\section{METHODS}

This systematic review was conducted using the Preferred Reporting Items for Systematic Reviews and Meta-Analysis guidelines. ${ }^{24}$ There was no patient or public involvement in this review.

\section{Search strategy and data sources}

In January 2020, we searched peer reviewed and grey literature investigating the impact of polio SIAs on routine immunisation systems. An initial scoping search was conducted in OVID Medline by an experienced information specialist (CK), and search terms refined in consultation with the senior author (MS). The following databases were searched: Ovid MEDLINE All including Epub Ahead of Print, In-Process \& Other Non-Indexed Citations, Daily and Versions (1946-10 January 2020), 
Ovid Embase (1974-8 January 2020), Cumulated Index to Nursing and Allied Health Literature (1982-January 2020), Cochrane Library Database of Systematic Reviews Issue 1 of 12, January 2020, Cochrane Library Central Register of Controlled Trials Issue 1 of 12, January 2020, Global Health (1910-Week 1 2020), Scopus (1823January 2020) and Latin-American and Caribbean System on Health Sciences Information (1982-January 2020). The search terms related to the topics of polio, SIAs and routine immunisation activities (online supplemental file $1)$. Where possible, both controlled vocabulary and freetext terms were used. The latter were particularly used to capture the myriad of terms used to describe both SIAs and routine immunisation programmes. Where necessary, adjacency operators were used to slightly increase specificity by ensuring relevant search terms could be located within a certain number of words from each other, which assisted in reducing false hits. Truncation was used to ensure variant endings of terms were included. The WHO's AFROLIB database (the WHO Regional Office for Africa's library database) was searched for grey literature reports. Articles were also identified by snow-balling through references of full-text included studies. Content area experts were approached for grey literature articles that would be relevant for inclusion, however, no further articles were sourced.

The WHO Region of Americas was the first region to achieve polio elimination in $1994 .{ }^{4}$ The searches were limited by publication year from 1994, in order to focus on studies conducted during the modern era of polio eradication. To minimise the introduction of bias, no language limits were applied. The final database search was conducted on 27 January 2020. The final grey literature search was conducted on 29 February 2020. The Ovid MEDLINE search strategy, including all terms used is available in online supplemental appendix 1.

\section{Inclusion and exclusion criteria}

Studies were included if they reported on primary and/ or operational data on polio SIAs (including both SIAs as part of outbreak response to WPV or cVDPV, or as part of immunisation mop-up activities) and included outcome data on either coverage/doses administered for vaccines provided under EPI (eg, measles containing vaccines, BCG, DTP) or data on other immunisation system indicators that are critical to health systems mainly finance, workforce training and capacity building and improvement of integrated health services (such as community engagement, increase in hospital beds and cold chain systems) as an adjunct to the polio SIAs. These key outcomes were selected as indicators that contribute to and can be used to measure the effectiveness and efficiency of immunisation programmes and health systems. ${ }^{25}$

Items were excluded if they were published before 1994 or data collection occurred prior to 1994 (as this time period was out of scope of our study aim). Animal studies, individual case studies, modelling studies and those reporting on only on secondary data analyses were also excluded.

\section{Study selection and screening}

Using Rayyan (https:/ / rayyan.qcri.org/ ${ }^{26}$ three reviewers $(\mathrm{KD}, \mathrm{BA}$ and $\mathrm{PM})$ independently reviewed article titles and abstracts. Authors KD, BA and AV conducted a fulltext review of articles that appeared to meet the inclusion criteria. Disagreements were resolved by discussion and consensus, and if required with input from the senior author (MS) to resolve any differences. For articles that were not in English, we used Google Translate (https:// translate.google.com/) for translation of the abstract and sought assistance from colleagues who were proficient in the language for assessment of full texts.

\section{Quality appraisal}

To the best of our knowledge, there are no critical appraisal tools which are specifically designed for assessing the quality of programmatic field-based studies. Therefore, qualitative studies were assessed using the Joanna Briggs Institute (JBI) critical appraisal tool checklist for qualitative research. ${ }^{27}$ Cross-sectional studies were assessed using the adapted Newcastle-Ottawa Scale for case-control studies by Herzog et al. ${ }^{28}$ Intervention studies were assessed using the JBI critical appraisal tool checklist for quasi-experimental research. ${ }^{29}$ Studies containing both qualitative and quantitative data were assessed using both tools. Two independent reviewers conducted the quality appraisal (AV and $\mathrm{KD}$ or $\mathrm{BA}$ ).

\section{Data extraction and synthesis}

A data extraction sheet was piloted and fields refined in consultation with several authors (MS, CK, KD and BA). Data extraction fields included standard information such as study design, target population size, location and limitations. Additional information was collected on data on SIAs, immunisation coverage for polio and non-polio antigens, incidence and prevalence of polio and other vaccine-preventable diseases, financial expenditures, human health resources including workforce training/ strengthening and delivery of health services. Data were extracted independently using an excel-based data extraction sheet. Author AV extracted data from all articles, BA extracted quantitative articles and $\mathrm{KD}$ extracted from qualitative articles. Other authors (MS and CK) were consulted about extraction in relation to some articles.

We identified and compared countries where polio was endemic compared with where it was non-endemic, due to the expectation that a higher number of SIAs are conducted in polio endemic countries. Due to the heterogeneity of studies (study designs and data collected), quantitative and statistical analyses were not feasible. Subsequently, we undertook a narrative synthesis of the available evidence.

To map the geographical locations of the included studies, shape files from the R package tmap were used. ${ }^{30}$ 


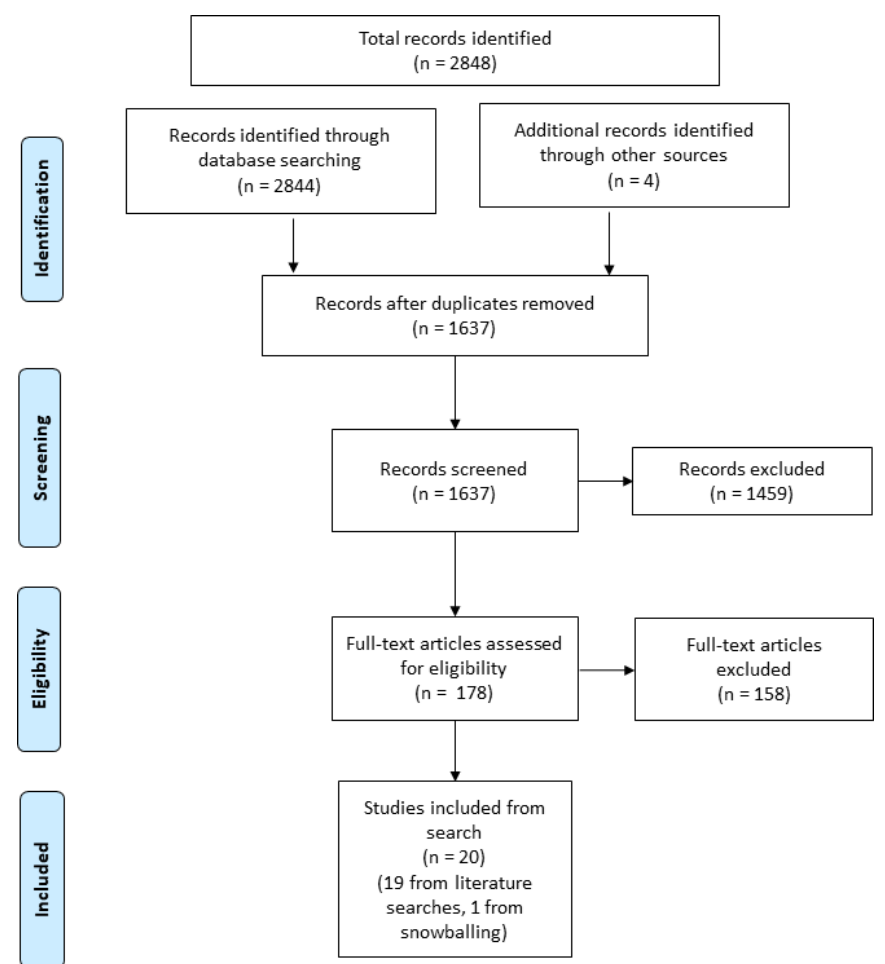

Figure 1 PRISMA flow chart to select included studies. PRISMA, Preferred Reporting Items for Systematic Reviews and Meta-Analyses.

Data on polio elimination certification year were sourced from the GPEI. ${ }^{31}$

\section{RESULTS}

The searches identified 1637 unique articles. Following the initial screening for titles and abstract 178 articles were included for full-text review (figure 1). A total of 20 unique studies were eligible and included in this review,
19 identified through searches and 1 identified through reference snowballing. Figure 2 represents the geographical field locations of where polio SIAs were delivered in the final included studies along with the decade the last recorded case of indigenous WPV was reported in each country.

The key characteristics of included studies are summarised in table 1 . Included studies ranged in geographical scope from single camp sites or communities, to entire WHO regions and several countries. The majority of included studies were based in the WHO AFRO region (14/20 studies, $70 \%)$. In $75 \%(15 / 20)$ of included studies, the primary rationale and listed reason for conducting SIAs was to boost immunisation coverage in areas with low coverage and uptake, either for specific subpopulations or whole countries. Other intervention contexts included assessing accuracy of administrative coverage data or polio eradication campaigns generally (table 1). The majority of the included studies $(95 \%$, 19/20) outlined some author identified limitations. These limitations were primarily related to operational issues, including a paucity of fit for purpose methods and tools for data collection, limited time periods of data collection, self-report biases, language barriers, sample size and limited generalisability of results. Age-specific data on immunisation coverage were available for $70 \%$ $(14 / 20)$ of studies, and in all of those were conducted in children aged $\leq 5$ years (online supplemental table 1 ). Data on delivery of routine immunisation during SIAs were available for $80 \%(16 / 20)$ studies and were accompanied by efforts towards increasing community engagement and public awareness in 45\% (9/20) of studies.

Table 2 and online supplemental table 2 summarise the outcome measures included in each study, the direction and nature of impact SIAs had on immunisation

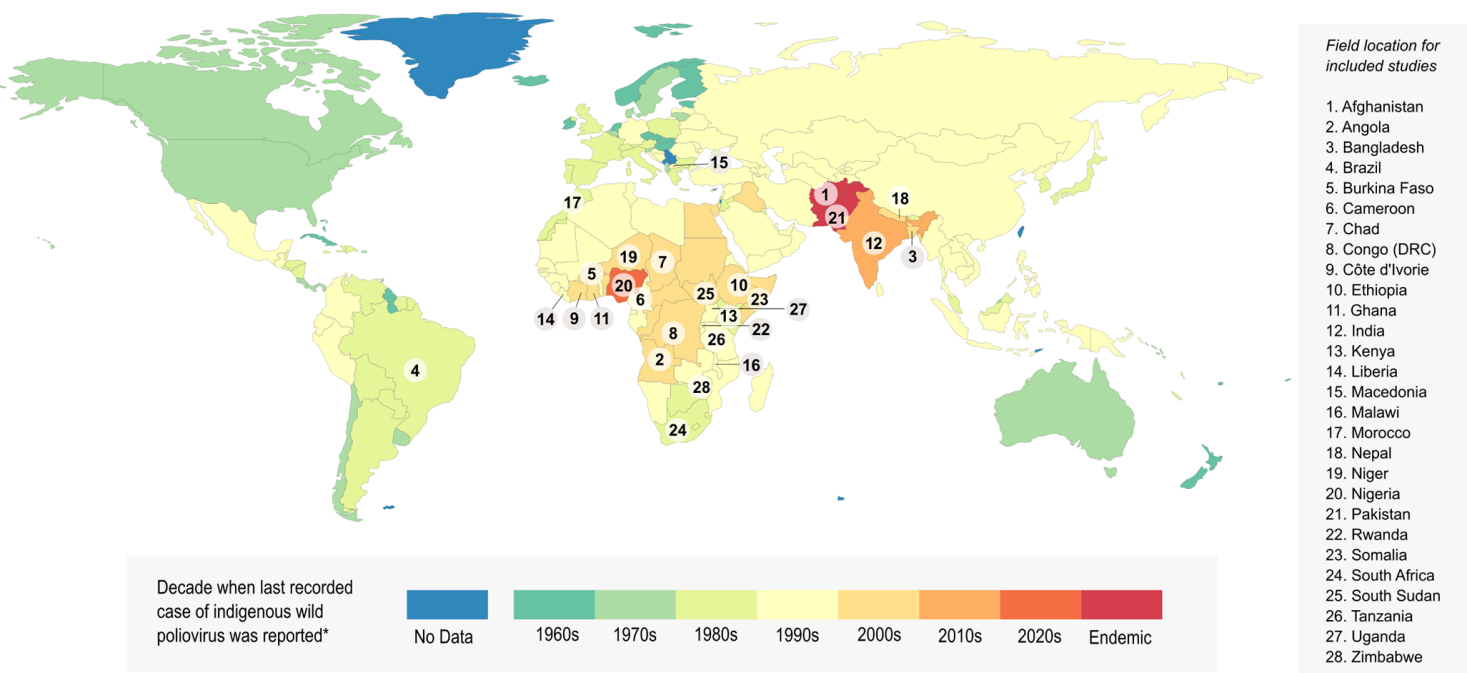

Figure 2 Timeline of global polio eradication efforts and study location for included papers the decade in which the last case of indigenous wild poliovirus was reported for each country is presented in different colours. Data from each country numbered were analysed by at least one study identified as meeting the inclusion criteria of our systematic review. Data on polio elimination certification year were sourced from the Global Polio Eradication Initiative. The figure was adapted from Our World in Data. ${ }^{66}$ 


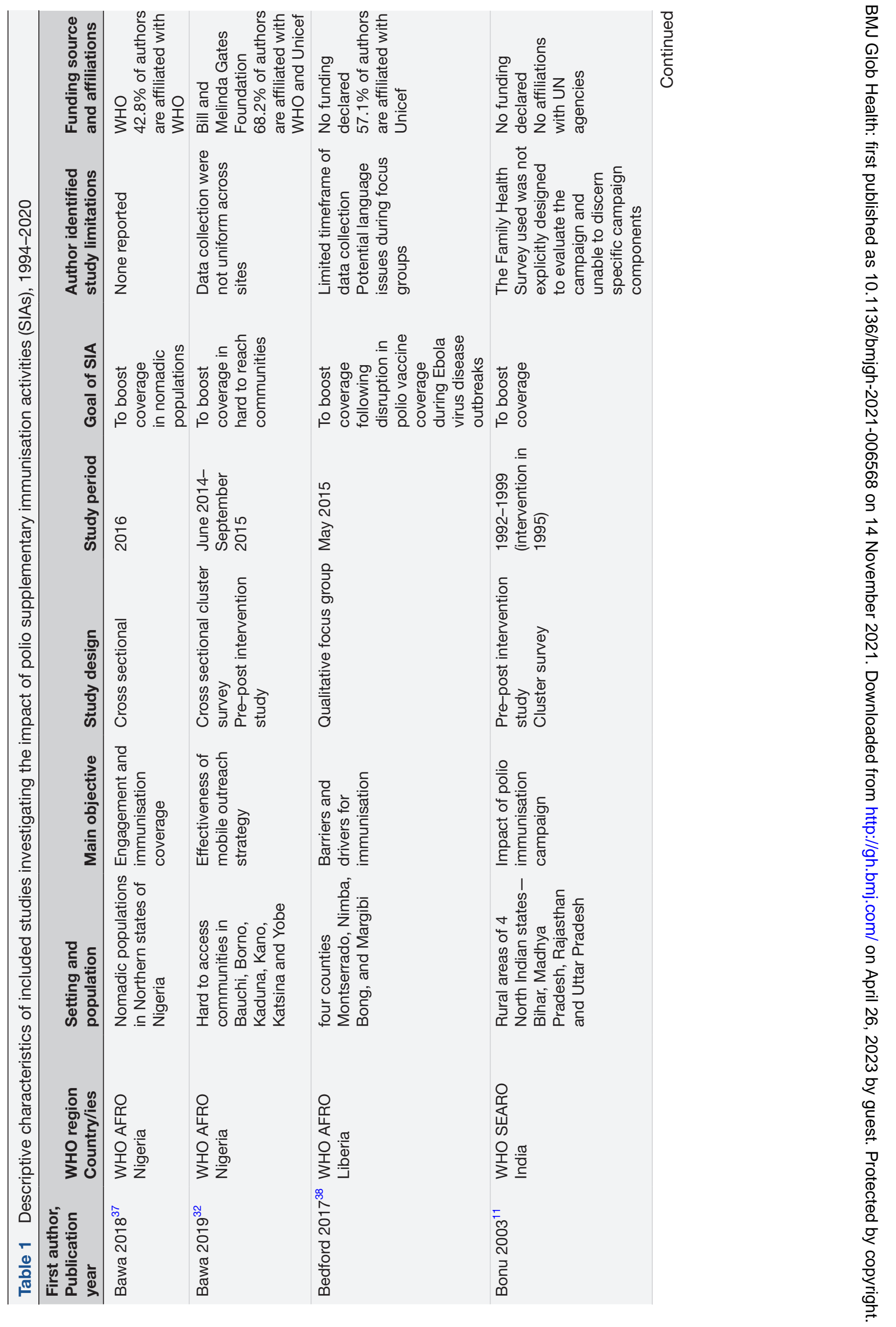




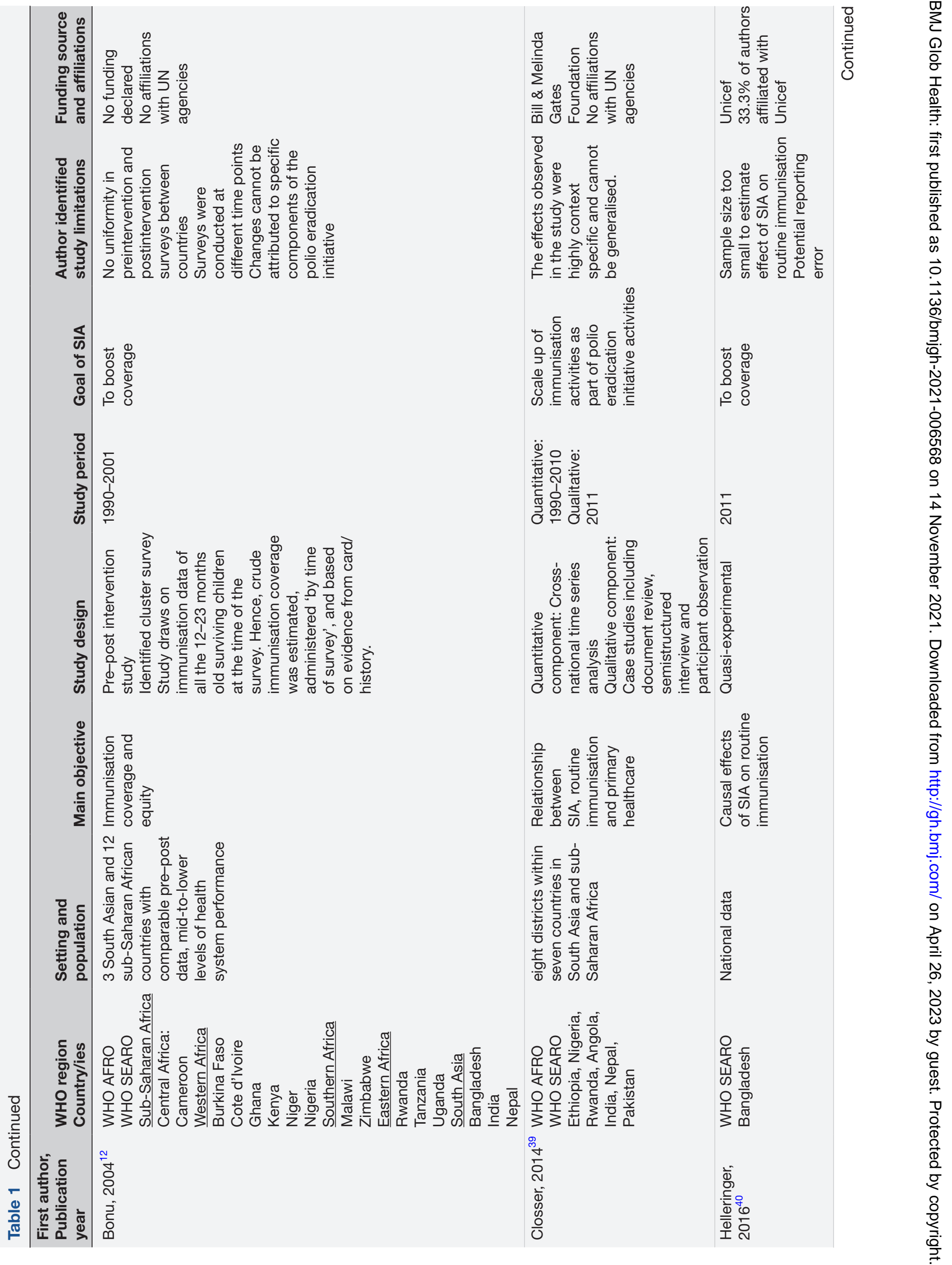




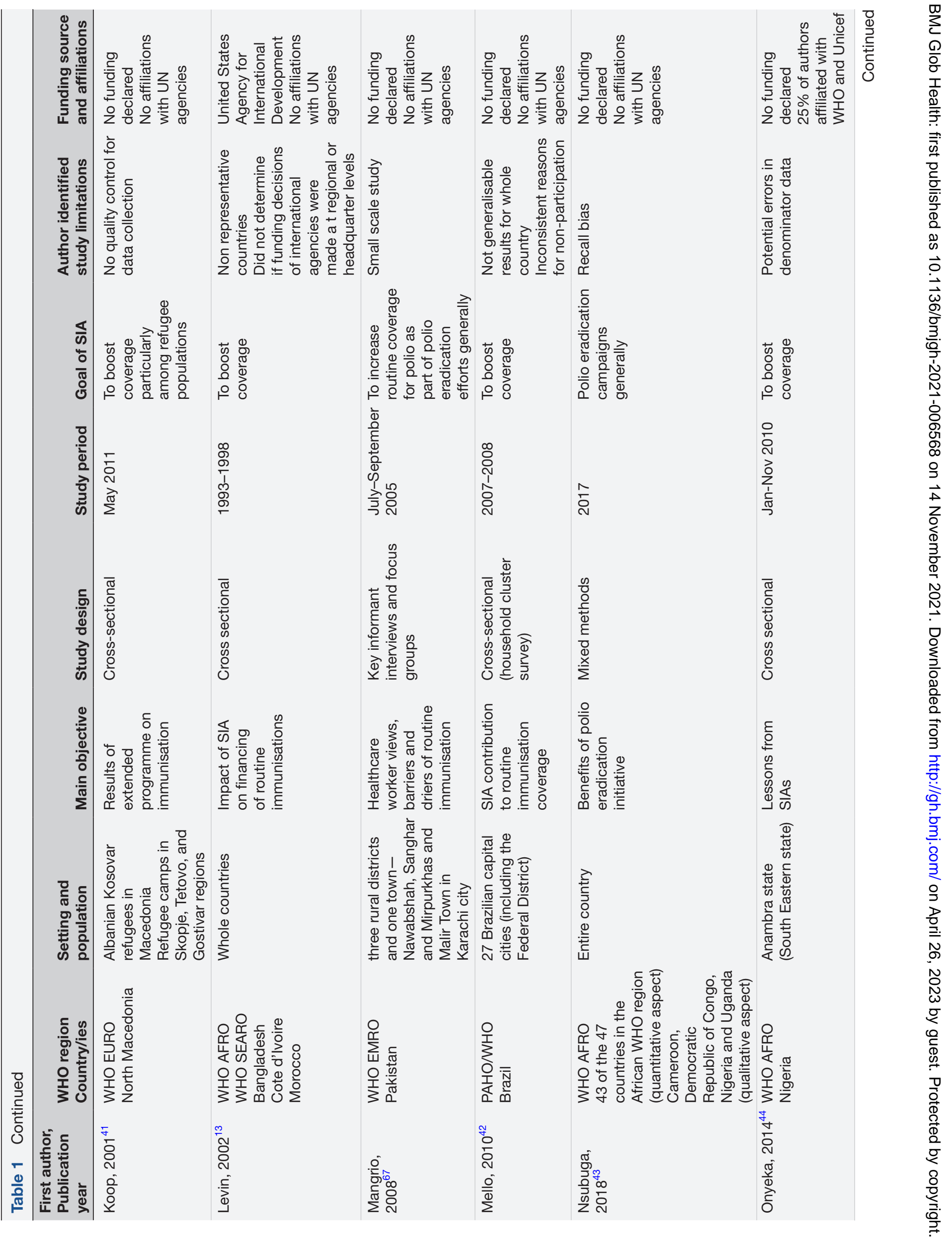




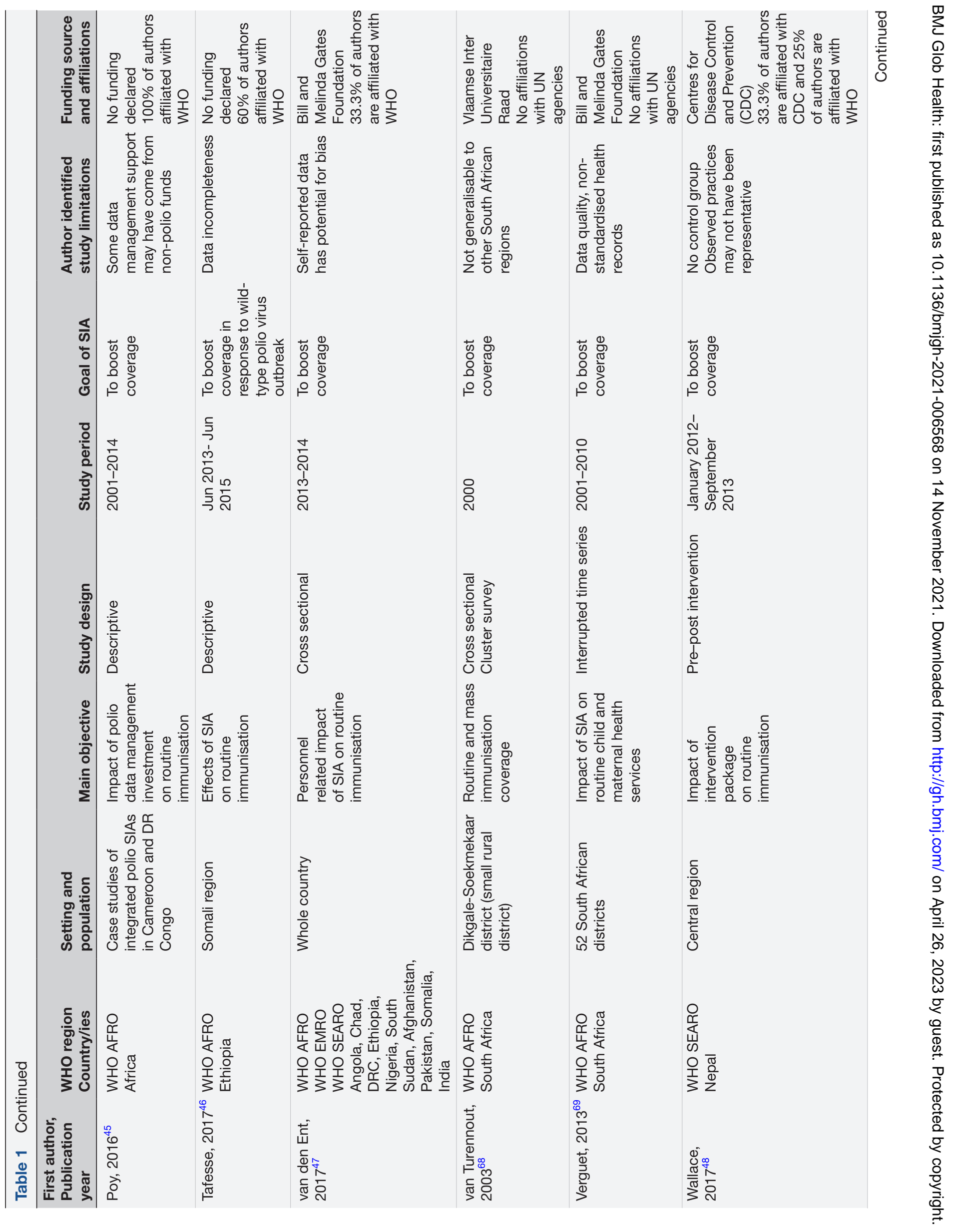




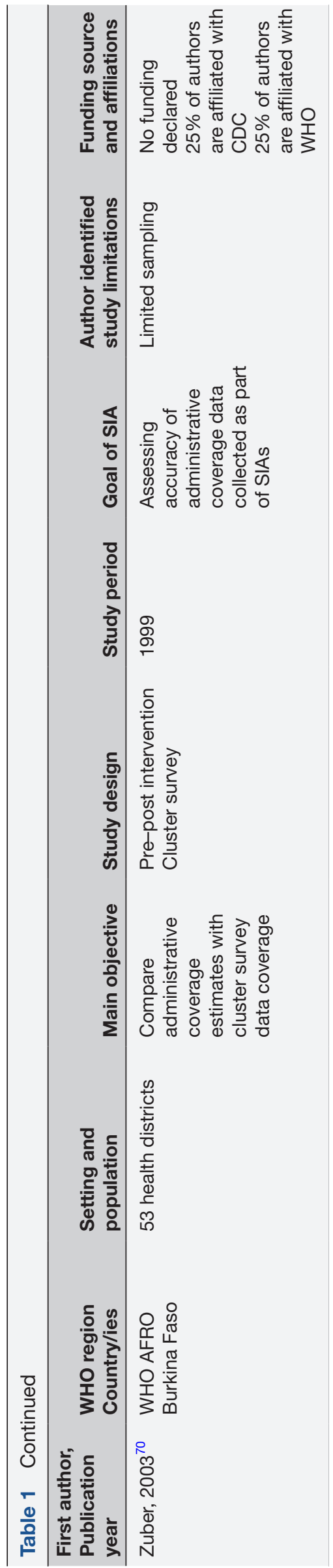

coverage (polio and non-polio antigens), financial expenditure, health workforce training or health service delivery. Data on coverage were included in 14/20 (70\%) studies, financial outcomes in 2/20 (10\%) studies, workforce implications in 13/20 (65\%) studies and impacts on health service delivery in $17 / 20(85 \%)$ studies. No study included data on incidence of polio. While not part of the original data extraction template, we found $4 / 20$ $(20 \%)$ studies reported a benefit on vaccine preventable diseases and other disease surveillance systems.

Due to the variability in the type of studies, reporting of results and due to different reasons for implementation of SIAs, including the country context where the studies were undertaken, the overall effect could not be determined. Nine of the 20 included studies were conducted either in one or multiple countries with endemic polio virus transmission at the time of their data collection. Of these nine, four reported only positive outcomes on their outcomes of interest, no study reported only negative impacts, and five reported neutral or mixed impacts of SIA's on their outcomes.

The impact of polio SIAs on increasing routine immunisation coverage or doses delivered was positive in seven studies, neutral in three studies, negative in one and inconclusive in one. The studies that did not find improvements in non-polio vaccine coverage discussed significant drop-out between doses (where coverage was defined as complete vaccination), limitations of not having a comparator group, context-specific deterioration of broader health systems and macro level political and economic barriers to improving vaccine uptake.

Only two studies included financial outcomes. In one multicountry study, ${ }^{13}$ funding increased by $11.1 \%$ in Bangladesh, $4.4 \%$ in Cote d'Ivore and $7.4 \%$ in Morocco, particularly for routine immunisation and other population health programmes. No changes in availability of funding were reported in other countries. A sustained increase in funding support for integrated delivery of primary healthcare services was reported in another multicountry report from the African region. ${ }^{32}$

Workforce is a critical factor in the success of any health programme. We found reports of increased capacity building, training and knowledge-based capacity associated with SIA implementation, often when there was concurrent increased recruitment instead of redeployment of existing staff. However, in studies without increased recruitment or in studies with large numbers of additional campaigns per year, decreased staff satisfaction was reported (two studies). We found a mixture of positive and negative impacts of SIAs on routine health service provision. Positive impacts included increases in community awareness about immunisation or routine other health services (five studies) and increase in the provision of other non-vaccination related health services (eight studies), especially in hard to reach areas. This was achieved through increases in resourcing or capacity development. In contrast, negative impacts and disruptions to routine health services were reported in four 
Table 2 Outcome measures included and direction of impact of supplementary immunisation activities (SIAs) on routine immunisation and health system

\begin{tabular}{|c|c|c|c|c|}
\hline $\begin{array}{l}\text { First author } \\
\text { Publication year } \\
\text { WHO Region }\end{array}$ & $\begin{array}{l}\text { Impact on routine immunisation } \\
\text { (overall conclusion) }\end{array}$ & Financial investment & $\begin{array}{l}\text { Human health resources } \\
\text { (workforce strengthening) }\end{array}$ & Health service delivery \\
\hline $\begin{array}{l}\text { Bawa et } a l^{37} 2018 \text { WHO } \\
\text { AFRO }\end{array}$ & $\widehat{\bigcup}$ & NA & 仓Capacity building \& training & $\begin{array}{l}\text { 仓Child \& maternal health } \\
\text { interventions }\end{array}$ \\
\hline $\begin{array}{l}\text { Bawa et al }{ }^{32} 2019 \text { WHO } \\
\text { AFRO }\end{array}$ & $\widehat{\imath}$ & $\begin{array}{l}\text { 仓Sustained funding } \\
\text { for integrated primary } \\
\text { healthcare services }\end{array}$ & $\begin{array}{l}\text { 仓Training for surveyors, nurses, } \\
\text { midwives, community health } \\
\text { workers }\end{array}$ & $\begin{array}{l}\text { 仓Healthcare delivery to } \\
\text { undeserved areas } \\
\text { 仓Awareness in caregivers } \\
\text { 仓Access to mobile healthcare } \\
\text { services } \\
\text { 仓Mobile routine immunisation } \\
\text { service }\end{array}$ \\
\hline $\begin{array}{l}\text { Bedford et } a l^{38} 2017 \text { WHO } \\
\text { AFRO }\end{array}$ & $\widehat{\bigcup}$ & NA & NA & $\begin{array}{l}\text { 仓Community awareness \& } \\
\text { engagement with paediatric } \\
\text { vaccination } \\
\text { Awareness in caregivers }\end{array}$ \\
\hline $\begin{array}{l}\text { Bonu et al }{ }^{11} 2003 \text { WHO } \\
\text { SEARO }\end{array}$ & $\Leftrightarrow$ & NA & NA & NA \\
\hline $\begin{array}{l}\text { Bonu et al }{ }^{12} 2004 \text { WHO } \\
\text { AFRO WHO SEARO }\end{array}$ & $\stackrel{\overbrace{\Downarrow}^{\leftrightarrow}}{\text { (depending on region) }}$ & NA & NA & Awareness about immunisation \\
\hline $\begin{array}{l}\text { Closser et }\left.a\right|^{39} 2014 \text { WHO } \\
\text { AFRO WHO SEARO }\end{array}$ & Inconclusive & NA & $\begin{array}{l}\text { 仓Capacity building \& training } \\
\qquad \text { Broadening knowledge } \\
\sqrt{\text { Worker satisfaction in areas with }} \\
>4 \text { campaigns per year }\end{array}$ & 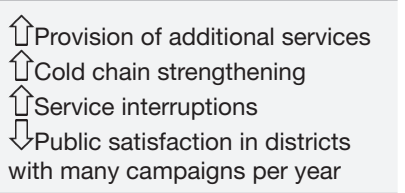 \\
\hline $\begin{array}{l}\text { Helleringer et } a{ }^{40} 2016 \\
\text { WHO SEARO }\end{array}$ & $\widehat{\bigcup}$ & NA & NA & $\begin{array}{l}\text { 仓Use of routine immunisation } \\
\text { services }\end{array}$ \\
\hline $\begin{array}{l}\text { Koop et al }{ }^{41} 2001 \text { WHO } \\
\text { SEARO }\end{array}$ & $\widehat{\bigcup}$ & NA & 仓Healthcare worker recruitment & $\begin{array}{l}\text { 仓Access to healthcare via weekly } \\
\text { clinics } \\
\text { 仓Support for other disease control } \\
\text { 仓Service delivery, communications } \\
\text { \& community engagements }\end{array}$ \\
\hline $\begin{array}{l}\text { Levin et } a^{13} 2002 \text { WHO } \\
\text { AFRO WHO SEARO }\end{array}$ & NA & $\begin{array}{l}\text { 仓Financing for } \\
\text { routine immunisation } \\
\& \text { population health } \\
\text { programmes (some } \\
\text { regions only) No impact } \\
\text { in some regions }\end{array}$ & NA & NA \\
\hline $\begin{array}{l}\text { Mangrio et al }{ }^{67} 2008 \mathrm{WHO} \\
\text { EMRO }\end{array}$ & NA & NA & $\begin{array}{l}\text { 仓Healthcare worker mobility } \\
\text { Staff dissatisfaction \& competition }\end{array}$ & $\begin{array}{l}\oiiint_{\text {Detrimental impact on routine }} \\
\text { immunisation, due to reassigned } \\
\text { staff }\end{array}$ \\
\hline $\begin{array}{l}\text { Mello et al }{ }^{42} 2010 \text { PAHO/ } \\
\text { WHO }\end{array}$ & $\widehat{\mho}$ & NA & NA & 仓Routine health service delivery \\
\hline $\begin{array}{l}\text { Nsubuga et al }{ }^{43} 2018 \\
\text { WHO AFRO }\end{array}$ & NA & NA & 仓Skilled workforce & $\begin{array}{l}\text { 仓Routine services due to } \\
\text { increased capacity } \\
\text { JPredicted disruptions after } \\
\text { withdrawal }\end{array}$ \\
\hline $\begin{array}{l}\text { Onyeka et al }{ }^{44} 2014 \text { WHO } \\
\text { AFRO }\end{array}$ & NA & NA & $\begin{array}{l}\text { 仓Capacity building \& training } \\
\text { 仓Recruitment of volunteers and } \\
\text { vaccinators from community }\end{array}$ & 仓Routine health service delivery \\
\hline Poy 2016 WHO AFRO & $\widehat{\bigcup}$ & NA & 仓Capacity building \& training & $\begin{array}{l}\text { 仓Integrated health interventions } \\
\text { and } \\
\text { 仓Data on vaccine preventable } \\
\text { diseases related activities }\end{array}$ \\
\hline Tafesse 2017 WHO AFRO & NA & NA & $\begin{array}{l}\text { 仓Capacity building \& training } \\
\text { 仓Deployment of technical } \\
\text { assistants }\end{array}$ & $\begin{array}{l}\text { 仓Service delivery, communications } \\
\text { and community engagement } \\
\text { 仓Cold chain }\end{array}$ \\
\hline
\end{tabular}


Table 2 Continued

\begin{tabular}{|c|c|c|c|c|}
\hline $\begin{array}{l}\text { First author } \\
\text { Publication year } \\
\text { WHO Region }\end{array}$ & $\begin{array}{l}\text { Impact on routine immunisation } \\
\text { (overall conclusion) }\end{array}$ & Financial investment & $\begin{array}{l}\text { Human health resources } \\
\text { (workforce strengthening) }\end{array}$ & Health service delivery \\
\hline $\begin{array}{l}\text { van den Ent } 2017 \text { WHO } \\
\text { AFRO WHO EMRO WHO } \\
\text { SEARO }\end{array}$ & NA & NA & 仓Capacity building \& training & $\begin{array}{l}\text { 仓Improved health systems, \& } \\
\text { awareness of routine immunisation } \\
\text { \& other health initiatives } \\
\text { (predicted reversal on withdrawal } \\
\text { of Global Polio Eradication Initiative } \\
\text { funded personnel) }\end{array}$ \\
\hline $\begin{array}{l}\text { van Turennout } 2003 \mathrm{WHO} \\
\text { AFRO }\end{array}$ & $\Leftrightarrow$ & NA & $\mho_{\text {Staff morale }}$ & $\begin{array}{l}\Leftrightarrow \text { Routine services as they } \\
\text { function well }\end{array}$ \\
\hline Verguet 2013 WHO AFRO & NA & NA & 仓Skilled workforce & $\begin{array}{l}\int_{\text {First antenatal care visits }} \\
\text { Maternal health visits } \\
\text { Regular health system } \\
\text { functioning due to diverting } \\
\text { resources }\end{array}$ \\
\hline $\begin{array}{l}\text { Wallance } 2017 \text { WHO } \\
\text { SEARO }\end{array}$ & NA & NA & $\begin{array}{l}\text { 仓Staff skills \& knowledge } \\
\text { 仓Informing children to return for } \\
\text { routine immunisation } \\
\Leftrightarrow \text { Immunisation technique }\end{array}$ & $\begin{array}{l}\text { 仓Health systems } \\
\text { 仓Supply chains } \\
\text { 仓Health information systems }\end{array}$ \\
\hline Zuber 2003 WHO AFRO & NA & NA & NA & NA \\
\hline
\end{tabular}

studies, particularly when additional staff resourcing was not incorporated to deliver SIAs and staff were redeployed. Two of these studies (Mangrio et al and Nsubuga et al) were conducted in polio endemic countries, Pakistan and Nigeria.

On examination of funding source and author affiliations, we found 10 included studies were funded by the WHO or UNICEF or included authors from these organisations. These studies reported only positive impacts of SIAs on outcomes, none of these studies reported negative or mixed impacts of SIAs. Of all the 12 studies reporting only positive impacts of SIA, three studies included no authors affiliated with WHO or UNICEF. Only two studies included a conflicts of interest disclosure.

Two independent reviewers conducted quality assessment of all studies. From a research quality appraisal perspective, many studies scored low on quality but this was likely due to absence of data reporting, rather than a lack of operational rigour. On applying the JBI's critical appraisal tool, qualitative studies were graded lower due to the lack of stated theoretical framework, or a statement locating the researchers' cultural framework. Quantitative studies were graded lower because of lack of blinding, lack of information about completeness of follow-up, other interventions being applied at the same time or a lack of controlling for confounding (due to the operational nature of the studies), or lack of statements about the representativeness of the sample or nonrespondents. All studies included programmatic data, which could not be accurately assessed using these quality assessment tools. To prevent inappropriate assessment regarding the value of the studies summary scores were not presented.

\section{DISCUSSION}

In this systematic review, we report on the role polio SIAs had in strengthening immunisation systems including delivery of routine immunisation and other immunisation related aspects of the health system. We found mixed evidence on whether polio SIAs contributed towards increases in immunisation coverage for non-polio vaccines and strengthening of health systems in-terms of service delivery, human health resources including workforce strengthening, and financial investment into immunisation systems. Our findings are consistent with previous studies and reviews, ${ }^{143}$ and reiterate the need to ensure that vertical eradication efforts and mass vaccination campaigns such as those for COVID-19 are delivered in parallel with routine immunisation to ensure health systems are strengthened. ${ }^{34}$

Our systematic review provides an important evidence synthesis update to the 1997 literature review study by Dietz and Cutts that was unable to conclude if mass immunisation campaigns were useful at increasing coverage or a cost-effective strategy to improve immunisation systems. ${ }^{18}$ A 1993 study examining polio vaccination under the EPI in the Americas region focused on countries that had ongoing transmission of polio virus in 1985, found that polio vaccination had an overall positive impact on the health system, particularly on social 
mobilisation, but gaps were identified around integration of immunisation activities into routine health services. ${ }^{35}$

Another multicountry study, conducted in 1999, pooled data from two large field studies and three supplementary reports from several countries. ${ }^{14}$ It found 'positive synergies' between polio eradication initiatives and health systems, and that these synergies could be better utilised. While there was broad consensus on the benefits of including vitamin A supplementation in relevant countries, there was limited quantitative data on other impacts on health systems, and that most available data were qualitative, country-specific and not generalisable. ${ }^{14}$

The primary outcome for this study was data on immunisation coverage for polio and non-polio vaccines. Of the 20 included studies, 13 reported data on polio delivery/coverage following SIAs and 12 reported data on delivery/coverage of non-polio vaccines including measles, Hepatitis B, measles, mumps and rubella, diphtheria, tetanus and pertussis, Haemophilus influenzae type b and 5-in-1, suggestive of a positive impact. In two studies, vitamin A delivery as an adjunct to measles vaccination and deworming tablets were reported. Importantly, no vaccination data were collected or reported in six studies. In most studies, data were reported as number of vaccine doses delivered, rather than population coverage; or coverage estimates were calculated by authors based on other data presented. While the primary goal of SIAs is to deliver vaccines to target populations irrespective of their immunisation history, ${ }^{36}$ examining any impact on uptake of routine immunisation in crucial to determine the impact of eradication efforts including SIAs and overall performance of the health system. None of the studies investigated longer term impact on routine immunisation coverage, workforce development or changes to delivery of health services to evaluate the implementation and effectiveness of SIA campaigns.

We found evidence of increased technical capacity and health services delivery particularly in difficult to access areas, increased caregiver awareness and social mobilisation about immunisation and greater access and consistency in routine health services. ${ }^{12}{ }^{32} 37-48$ There was also evidence to support that polio SIAs were leveraged for improving the delivery of non-polio vaccines. However, improvement in routine immunisation was not reported in all studies, suggesting there are still missed opportunities to strengthen immunisation systems through the financial and resource investment of polio SIAs. ${ }^{43} 4950$ Additionally, studies did not collect data over multiple time points and therefore sustainability of these public health interventions and long-term impacts were not measured.

A previous systematic review of eight African countries found an increase in coverage for routine vaccines delivered as part of the EPI over several years of GPEI implementation, health services delivery, programme management and capacity building. ${ }^{51}$ Although not specified, the studies included in this review which reported positive impacts most likely relied on additional staff resourcing, as studies that did not include additional resources to implement reported negative impacts on health service delivery. For example, SIAs in South Asia (Pakistan) and sub-Saharan Africa, including persistently polio endemic areas like Nigeria, with greater than four campaigns per year resulted in decreased worker satisfaction, particularly in terms of motivation and fatigue. ${ }^{39}$ These findings highlight that SIAs are likely to have more positive outcomes on the health system where the routine immunisation system may already be better performing, in contrast to those where there are ongoing challenges with routine immunisation. Similar findings have been reported before and should be considered while designing and implementing SIAs. ${ }^{52}$

A review of data from the Western Pacific Region between 1990 and 1994 demonstrated that activities conducted under the GPEI led to a noticeable increase in coverage for BCG, DTP2 and measles containing vaccines in many countries. ${ }^{16}$ While direct effects are difficult to measure, an investment into the healthcare infrastructure across disease surveillance, inter-sectoral collaborations and cooperation between politicians, government officials, healthcare workers and the public were attributed as the drivers for these successes. ${ }^{16}$ Data from a recent cluster randomised trial in Pakistan demonstrated that a strategy of community mobilisation and targeted community-based health and immunisation camps during polio SIAs increased vaccine coverage for polio to $82 \%$ compared with $75 \%$ in the control arm wherein children received OPV alone. ${ }^{53}$ Similar effects were observed on the mean proportion of routine childhood immunisation doses that each child received, which increased to $52 \%$ in intervention arm, compared with $43 \%$ in children who received OPV alone (with pre-SIA baseline of $39 \%) .^{53}$

A study examining the utility of polio national immunisation days (SIAs) to deliver vitamin A supplements found SIAs were a beneficial way of reaching children, as well as raising awareness, enhancing technical capacity, improving assessment and establishing reporting systems. ${ }^{54}$ The study provided a framework to use polio SIAs as a platform for delivering preventive health programmes including routine immunisation, in particular on advocacy, social mobilisation, increase in technical capacity, strengthening laboratory systems and reporting mechanisms. These findings align with GPEI goals which advocate for activities to be delivered to strengthen national immunisation programmes and health infrastructure. The new Polio Eradication Strategy 2022-2026 also encourages integration of SIAs with social and health programmes, including routine immunisation. ${ }^{19}$

Our study was not specifically designed to examine the relationship of author affiliations or funding sources (potential conflicts of interest) on the reported impact of polio SIAs. However, incidental findings from our analyses found that of the 20 included studies, 11 studies had potential conflicts of interest based on authorship 
(WHO, UNICEF, US Centers for Disease Control and Prevention) and declared funding source. While these studies typically reported positive impacts of polio SIAs, it also signifies a partnership model between agencies and institutions working on polio programmes. In addition three studies without these potential conflicts of interest also reported only positive impacts. Negative and mixed impact of polio SIAs were only reported by studies without these potential conflicts of interest. The types of outcomes investigated by studies with and without potential conflicts had overlaps and similarities. A difference between studies was that those with no potential conflicts of interest were the only studies to examine and report health worker morale and satisfaction, which was considered negatively impacted by polio SIAs in several studies. These mixed findings require further investigation and research into the implementation of global programmes, as has been discussed previously. ${ }^{55-57}$ Conflicts of interest cannot always be excluded, but declaration and management of interests can minimise bias and improve global health research practice.

We found a high degree of data heterogeneity in our review, which prevented us from undertaking statistical analyses of the data. Data varied across different regions, time periods, the purpose of conducting SIAs and outcome measures. The substantial variation between studies has been previously recognised as a limitation in reviews including different study designs in low-income and middle-income countries. ${ }^{58}$ Findings from our review are difficult to generalise due to the variability in data and country-specific quantitative data in the included studies.

The literature review by Dietz and Cutts also reported variation in data, and recommended identifying methods to evaluate SIAs to measure their usefulness. ${ }^{18}$ However, we did not find any tools or systematic studies to evaluate polio SIAs. A previous toolkit for assessing the impacts of measles eradication activities on immunisation services and health systems highlights inclusion of all relevant impacts and dimensions including those related to governance, planning and management, financing, human resources, logistics, procurement, information systems and management, disease surveillance and immunisation service delivery. ${ }^{59}$ The recently launched tools by the WHO on 'Prepare for COVID-19 vaccine introduction and post-introduction evaluation using the guidance, tools and trainings for national/subnational focal points and health workers developed by the Access to COVID-19 Tools Accelerator's Country Readiness and Delivery workstream' encourage and should serve as an impetus to develop standardised tools for implementing and evaluating SIAs and eradication efforts using quantitative and qualitative metrics. ${ }^{60}$

The strength of our systematic review includes robust high quality searches conducted by an experienced information specialist using nine databases, snowballing for relevant articles and contacting content area experts for other reports or grey literature. In addition, the introduction of bias was further minimised by independent screening and extraction by two reviewers, inclusion of non-English articles which were translated where required, the use of a multidisciplinary review team and inclusion of qualitative as well as quantitative studies. ${ }^{39}$ This review also provides valuable data synthesis of studies specifically published during the modern era of polio eradication (1994 onwards). Since the feasibility and usefulness of embarking on eradication initiatives is driven not just by biological aspects of disease prevention, but also cost-effectiveness analyses, programmatic feasibility, posteradication risk-assessments and impact on health system, this review also provides timely evidence to support decision making for polio eradication activities.

There were some limitations stemming from the timing when this systematic review was undertaken and the programmatic nature of polio SIAs roll-out. We attempted to contact polio experts for grey literature, but data collection for this review overlapped with year one of the COVID-19 pandemic, which limited our ability to source unpublished reports so it is possible that some data were not captured by this study. There is likely to also be publication bias attributable to some countries and regions having greater motivation and capacity to publish findings from polio SIAs than others. An additional limitation of our study is that by focusing on data from 1994, we have missed early studies. However, as the focus of this study was on synthesising contemporary evidence to guide operational policies and practice in the future, we believe this study summarises and provides updated empirical evidence to enable the design of SIAs including polio, measles and COVID-19 to adopt a health systems approach. For example implementing processes to record data on vaccinated persons to enable accurate measurement of coverage data or retention of staff employed specifically for SIAs as part of routine immunisation services. ${ }^{47}$

Study designs varied and often employed a pragmatic methodology to respond to acute public health events in the 'real world', which are inherently different to conducting a planned research study. ${ }^{61}$ We attempted to critically appraise the studies using three different tools-the JBI critical appraisal tool checklist for qualitative research, ${ }^{27}$ the modified Newcastle-Ottawa Scale for case-control studies by Herzog $e t a l^{28}$ and the JBI critical appraisal tool checklist for quasi-experimental research. ${ }^{29}$ However, we were unable to justly appraise the studies as these tools were not considered 'fit-for-purpose' to assess the rigour of operational or field-based studies. Instead these tools were primarily designed for planned research studies, and were not well suited to programmatic studies aimed at responding to acute public health events including outbreaks. For this reason, we did not exclude studies that scored 'lower quality' or 'higher risk of bias', as they contained valuable programmatic information. As an example, the 'assessment of outcome' (immunisation status) in the included studies was frequently based on self-report from mothers. While this is standard practice in low and middle income countries, the quality 
assessment tool would score this as $0 / 2$, with vaccine registry or hospital recorded required to score $2 / 2$.

Finally, through our searches, we identified 255 articles which contained information on polio SIAs which were not included in this review as they did not meet all the inclusion criteria (data on delivery of routine immunisation or immunisation system indicators). This could be related to limited delivery of routine vaccines as part of SIAs or reporting of data in published literature, and disruption to existing health programmes during outbreaks. This is not exclusive to polio campaigns, and similar observations have been made during the delivery of measles SIAs or while responding to the COVID-19 pandemic. ${ }^{62}$ In settings like Pakistan, where polio is still endemic and significant proportion of children are undervaccinated and at risk of contracting polio and other vaccine preventable diseases, disruption from COVID-19 resulted in $\sim 52 \%$ reduction in daily vaccination visits during 23 March 2020-9 May 2020, compared with the prepandemic period. ${ }^{22}$ Globally, GPEI activities were disrupted for the initial few months of the pandemic, and since then significant efforts were made to re-start the campaigns by July 2020 with appropriate COVID-19 prevention measures in place. ${ }^{63}$ Increased preparedness and planning, the use of outbreaks and SIAs as platforms to deliver preventive public health programmes can create opportunities to strengthen immunisation system structures, and health systems. Our review indicates that investment in training, community education and engagement, and additional staffing are key ways to achieve this. While not directly examined in this systematic review, strategies for implementation and integration of SIAs could include utilisation monitoring tools or checklists that detail different aspect of SIA planning, who is responsible for elements of the programme, and how the efforts can be further incorporated into routine services.

Ensuring vertical health programmes including SIAs are delivered in parallel with routine immunisation, and monitoring their impact on immunisation systems and health systems is particularly critical at this time, as the world takes on the challenge of rolling-out COVID-19 vaccines-expected to be the largest and fastest vaccine roll-out ever undertaken. ${ }^{64} \mathrm{~A}$ recent World Bank report found that few countries will be able to use COVID-19 vaccine deployment to strengthen health systems and future-proof against future crises. ${ }^{65}$

\section{CONCLUSIONS}

Polio SIAs, while potentially disruptive to the delivery of routine health services, can provide a possible platform for strengthening health system capacity to deliver routine immunisation. Outcome data included in our review were heterogeneous, but indicated that in many settings, SIAs could be better leveraged for improving routine immunisation and immunisation systems. Key data from SIA planning and implementation, including identified high-risk populations and lessons learnt must be incorporated into national and subnational immunisation programme planning. To better enable this, we recommend programmatic support and guidance to deliver SIAs in a manner that strengthens the health system that is tailor-made but uses standardised tools to monitoring impact of SIAs on routine immunisation, across different pillars of the health system including governance, planning and management, financing, human resources, logistics, procurement, information systems and management, disease surveillance and immunisation service delivery.

\section{Author affiliations}

${ }^{1}$ The George Institute for Global Health, University of New South Wales, Sydney, New South Wales, Australia

${ }^{2}$ Sydney School of Public Health, Faculty of Medicine and Health, The University of Sydney, Sydney, New South Wales, Australia

${ }^{3}$ National Centre for Epidemiology and Population Health, ANU College of Health and Medicine, The Australian National University, Canberra, Australian Capital Territory, Australia

${ }^{4}$ Menzies School of Health Research, Charles Darwin University, Darwin, Northern Territory, Australia

${ }^{5}$ The Children's Hospital at Westmead Clinical School, Faculty of Medicine and Health, The University of Sydney, Sydney, New South Wales, Australia ${ }^{6}$ National Centre for Immunisation Research and Surveillance, The Children's Hospital at Westmead, Westmead, New South Wales, Australia

Twitter Amy Vassallo @amyjvassallo and Meru Sheel @merusheel

Acknowledgements We would like to thank Mr Peter Wnukowski-Mtonga for assistance for initial title and abstract screening. We would like to acknowledge $\mathrm{Dr}$ Kevin Yin for assistance with translation of articles.

Contributors All authors contributed to the conceptualisation, design and interpretation of the article. MS conceived and oversaw the work, CK designed and conducted the literature searches and provided advice resystematic review methods. KD, BA and AV screened the articles and conducted the quality assessment and extraction in consultation with CK and MS. AV, CK and MS conducted the data synthesis. AV, CK and MS wrote the first draft. All authors critically analysed findings, edited and contributed to critical review of the article. MS and AV are guarantors for this article.

Funding MK is funded by the Australian National Health and Medical Research Council (APP1145997). MS is funded by a research fellowship from the Westpac Scholars Trust.

Map disclaimer The inclusion of any map (including the depiction of any boundaries therein), or of any geographic or locational reference, does not imply the expression of any opinion whatsoever on the part of BMJ concerning the legal status of any country, territory, jurisdiction or area or of its authorities. Any such expression remains solely that of the relevant source and is not endorsed by BMJ. Maps are provided without any warranty of any kind, either express or implied.

Competing interests None declared.

Patient consent for publication Not applicable.

Ethics approval As this is a systemic review of published studies ethics committee approval was not required.

Provenance and peer review Not commissioned; externally peer reviewed.

Data availability statement All data relevant to the study are included in the article or uploaded as online supplemental information. All data relevant to this study are available in the article and/or in previously published research articles.

Supplemental material This content has been supplied by the author(s). It has not been vetted by BMJ Publishing Group Limited (BMJ) and may not have been peer-reviewed. Any opinions or recommendations discussed are solely those of the author(s) and are not endorsed by BMJ. BMJ disclaims all liability and responsibility arising from any reliance placed on the content. Where the content includes any translated material, BMJ does not warrant the accuracy and reliability of the translations (including but not limited to local regulations, clinical guidelines, 
terminology, drug names and drug dosages), and is not responsible for any error and/or omissions arising from translation and adaptation or otherwise.

Open access This is an open access article distributed in accordance with the Creative Commons Attribution Non Commercial (CC BY-NC 4.0) license, which permits others to distribute, remix, adapt, build upon this work non-commercially, and license their derivative works on different terms, provided the original work is properly cited, appropriate credit is given, any changes made indicated, and the use is non-commercial. See: http://creativecommons.org/licenses/by-nc/4.0/.

\section{ORCID iDs}

Amy Vassallo http://orcid.org/0000-0002-8473-7549

Meru Sheel http://orcid.org/0000-0001-5453-070X

\section{REFERENCES}

1 World Health Organization (WHO). WHA41.28 global eradication of poliomyelitis by the year 2000 1988, 2020. Available: https://www. who.int/ihr/polioresolution4128en.pdf [Accessed 11 Sep 2020].

2 Chard AN, Datta SD, Tallis G, et al. Progress Toward Polio Eradication - Worldwide, January 2018-March 2020. MMWR Morb Mortal Wkly Rep 2020;69:784-9.

3 Greene SA, Ahmed J, Datta SD, et al. Progress Toward Polio Eradication - Worldwide, January 2017-March 2019. MMWR Morb Mortal Wkly Rep 2019;68:458-62.

4 Pan American Health Organization. 25 years of being polio-free in the Americas, 2019. Available: https://www.paho.org/hq/index.php? option=com_content\&view=article\&id=15525:25-years-of-beingpolio-free-in-the-americas\&ltemid $=1926 \&$ lang $=$ en [Accessed Jan 2021].

5 Global Polio Eradication Initiative. Global polio eradication initiative: 2005 annual report. Geneva: WHO, 2005. http://www. polioeradication.org/content/publications/annualreport2005.asp

6 Polio Global Eradication Initiative. Supplementary immunization. Available: https://polioeradication.org/who-we-are/polio-endgamestrategy-2019-2023/supplementary-immunization/\#: :text=Mass\% 20immunization $\% 20$ campaigns $\% 2 \mathrm{C} \% 20$ known $\% 20$ as,the $\%$ 20 four\%20pillars\%20 of $\% 20$ eradication.\&text=The\%20idea\%20is $\%$ 20 to $\% 20$ catch,those $\% 20$ who\%20have\%20been\%20immunized [Accessed May 2021]

7 World Health Organization (WHO). Resurgence of wild poliovirus type 1 transmission and effect of importation into polio-free countries, 2002-2005. Weekly epidemiological record, 2006: 63-8.

8 Lee JW, Melgaard B, Hull HF, et al. Ethical dilemmas in polio eradication. Am J Public Health 1998;88:130-2.

9 Haenssgen MJ. Impact of high-intensity polio eradication activities on children's routine immunization status in northern India. Health Policy Plan 2017;32:800-8.

10 Clements CJ, Soakai TS, Sadr-Azodi N. A review of measles supplementary immunization activities and the implications for Pacific Island countries and territories. Expert Rev Vaccines 2017;16:161-74.

11 Bonu S, Rani M, Baker TD. The impact of the National polio immunization campaign on levels and equity in immunization coverage: evidence from rural North India. Soc Sci Med 2003:57:1807-19.

12 Bonu S, Rani M, Razum O. Global public health mandates in a diverse world: the polio eradication initiative and the expanded programme on immunization in sub-Saharan Africa and South Asia. Health Policy 2004;70:327-45.

13 Levin A, Ram S, Kaddar M. The impact of the global polio eradication initiative on the financing of routine immunization: case studies in Bangladesh, C te d'Ivoire, and Morocco. Bull World Health Organ 2002;80:822-8.

14 Loevinsohn B, Aylward B, Steinglass R, et al. Impact of targeted programs on health systems: a case study of the polio eradication initiative. Am J Public Health 2002;92:19-23.

15 Grabowsky M, Nobiya T, Ahun M, et al. Distributing insecticidetreated bednets during measles vaccination: a low-cost means of achieving high and equitable coverage. Bull World Health Organ 2005;83:195-201.

16 Aylward RB, Bilous J, Tangermann RH, et al. Strengthening routine immunization services in the Western Pacific through the eradication of poliomyelitis. J Infect Dis 1997;175 Suppl 1:S268-71.

17 Verguet S, Jassat W, Bertram MY, et al. Supplementary immunization activities (SIAs) in South Africa: comprehensive economic evaluation of an integrated child health delivery platform. Glob Health Action 2013;6:20056.
18 Dietz V, Cutts F. The use of mass campaigns in the expanded program on immunization: a review of reported advantages and disadvantages. Int J Health Serv 1997;27:767-90.

19 World Health Organization (WHO). Delivering on a promise. polio eradication strategy 2022-2026. Geneva: World Health Organization, 2021.

20 Adamu AA, Jalo RI, Habonimana D, et al. COVID-19 and routine childhood immunization in Africa: Leveraging systems thinking and implementation science to improve immunization system performance. Int J Infect Dis 2020;98:161-5.

21 Din M, Ali H, Khan M, et al. Impact of COVID-19 on polio vaccination in Pakistan: a Concise overview. Rev Med Virol 2021;31:e2190.

22 Chandir S, Siddiqi DA, Setayesh H, et al. Impact of COVID-19 lockdown on routine immunisation in Karachi, Pakistan. Lancet Glob Health 2020;8:e1118-20.

23 Chandir S, Siddiqi DA, Mehmood M, et al. Impact of COVID-19 pandemic response on uptake of routine immunizations in Sindh, Pakistan: an analysis of provincial electronic immunization registry data. Vaccine 2020;38:7146-55

24 Moher D, Liberati A, Tetzlaff J, et al. Preferred reporting items for systematic reviews and meta-analyses: the PRISMA statement. PLoS Med 2009;6:e1000097.

25 GAVI. Health systems goal indicators, 2019. Available: https:// www.gavi.org/our-impact/measuring-our-performance/2016-2020indicators/health-systems-goal [Accessed Jan 2021].

26 Ouzzani M, Hammady H, Fedorowicz Z, et al. Rayyan-a web and mobile APP for systematic reviews. Syst Rev 2016;5:210.

27 The Joanna Briggs Institute. The Joanna Briggs Institute critical appraisal tools for use in JBI systematic reviews: checklist for qualitative research. South Australia Joanna Briggs Institute, 2017.

28 Herzog R, Álvarez-Pasquin MJ, Díaz C, et al. Are healthcare workers' intentions to vaccinate related to their knowledge, beliefs and attitudes? A systematic review. BMC Public Health 2013;13:154.

29 The Joanna Briggs Institute. The Joanna Briggs Institute Critical Appraisal tools for use in JBI Systematic Reviews - Checklist for Quasi-Experimental Studies (non-randomized experimental studies). South Australia The Joanna Briggs Institute, 2017.

30 Tennekes M. tmap: thematic maps in R. J Stat Softw 2018;84

31 Polio Global Eradication Initiative. Polio free countries, 2016. Available: https://polioeradication.org/where-we-work/polio-freecountries/ [Accessed Fab 2021].

32 Bawa S, McNab C, Nkwogu L, et al. Using the polio programme to deliver primary health care in Nigeria: implementation research. Bull World Health Organ 2019;97:24-32.

33 Mogedal S, Stenson B. Disease eradication: friend or foe to the health system? synthesis report from field studies on the polio eradication initiatives in Tanzania. Nepal and the Lao People's Demcratic Republic Geneva: World Health Organisation, 2000.

34 World Bank Group. Assessing country readiness for COVID-19 vaccines - first insights from the assessment rollout. Washington DC, 2021.

35 Pan American Health Organization WHO. The impact of the expanded program on immunization and the polio eradication initiative on health systems in the Americas: final report of the "Taylor Commission", 1995.

36 Utazi CE, Thorley J, Alegana VA, et al. Mapping vaccination coverage to explore the effects of delivery mechanisms and inform vaccination strategies. Nat Commun 2019;10:1-10.

37 Bawa S, Afolabi M, Abdelrahim K, et al. Transboundary nomadic population movement: a potential for import-export of poliovirus. BMC Public Health 2018;18:1316.

38 Bedford J, Chitnis K, Webber N, et al. Community engagement in Liberia: routine immunization Post-Ebola. $J$ Health Commun 2017;22:81-90.

39 Closser S, Cox K, Parris TM, et al. The impact of polio eradication on routine immunization and primary health care: a mixed-methods study. J Infect Dis 2014;210 Suppl 1:S504-13.

40 Helleringer S, Asuming PO, Abdelwahab J. The effect of mass vaccination campaigns against polio on the utilization of routine immunization services: a regression discontinuity design. Vaccine 2016;34:3817-22.

41 Koop DG, Jackson BM, Nestel G. Results of the expanded program on immunization in the Macedonian refugee camps. Am J Public Health 2001;91:1656-9.

42 Mello MLR, Moraes JC, Barbosa HA. Participation in national polio immunization days: results of a vaccine coverage survey among children in 27 Brazilian cities. Rev Bras Epidemiol 2010;13:278-88.

43 Nsubuga P, Masiira B, Ibrahim L, et al. The contribution of the polio eradication initiative on the operations and outcomes of non-polio public health programs: a survey of programs in the African region. Pan Afr Med J 2018;31:207. 
44 Onyeka IN, Ilika AL, Ilika FN, et al. Experiences from polio supplementary immunization activities in Anambra state, Nigeria. Niger J Clin Pract 2014;17:808-13.

45 Poy A, Minkoulou E, Shaba K, et al. Polio eradication initiative contribution in strengthening immunization and integrated disease surveillance data management in who African region, 2014. Vaccine 2016;34:5181-6.

46 Tafesse B, Tekle E, Wondwossen L, et al. Effects of polio eradication activities on routine immunization: lessons from the 2013 outbreak response in Somali region of Ethiopia. Pan Afr Med J 2017;27:4.

47 van den Ent MMVX, Swift RD, Anaokar S, et al. Contribution of global polio eradication Initiative-Funded personnel to the strengthening of routine immunization programs in the 10 focus countries of the polio eradication and endgame strategic plan. $J$ Infect Dis 2017;216:S244-9.

48 Wallace AS, Rajendra B, Stewart S. Impact of an intervention to use a measles, rubella, and polio mass vaccination campaign to strengthen routine immunization services in Nepal. (Special Issue: Polio endgame \& legacy-implementation, best practices, and lessons learned. J Infect Dis 2017;216:S280-6.

49 Fields R, Dabbagh A, Jain M, et al. Moving forward with strengthening routine immunization delivery as part of measles and rubella elimination activities. Vaccine 2013;31 Suppl 2:B115-21.

50 Kamso J, Mvika ES, Ota MOC, et al. The contribution of the polio eradication initiative to narrowing the gaps in the health workforce in the African region. Vaccine 2016;34:5150-4.

51 Anya B-PM, Moturi E, Aschalew T, et al. Contribution of polio eradication initiative to strengthening routine immunization: lessons learnt in the WHO African region. Vaccine 2016;34:5187-92.

52 Alonge $\mathrm{O}$, Neel $\mathrm{AH}$, Kalbarczyk $\mathrm{A}$, et al. Synthesis and translation of research and innovations from polio eradication (stripe): initial findings from a global mixed methods study. BMC Public Health 2020;20:1176.

53 Habib MA, Soofi S, Cousens S, et al. Community engagement and integrated health and polio immunisation campaigns in conflictaffected areas of Pakistan: a cluster randomised controlled trial. Lancet Glob Health 2017;5:e593-603.

54 Goodman T, Dalmiya N, de Benoist B, et al. Polio as a platform: using national immunization days to deliver vitamin A supplements. Bull World Health Organ 2000;78:305-14.

55 Merriman R, Galizia I, Tanaka S, et al. The gender and geography of publishing: a review of sex/gender reporting and author representation in leading general medical and global health journals. BMJ Glob Health 2021;6:e005672.

56 Ghani M, Hurrell R, Verceles AC, et al. Geographic, subject, and authorship trends among LMIC-based scientific publications in high-impact global health and general medicine journals: a 30-month bibliometric analysis. J Epidemiol Glob Health 2021;11:92-7.
57 Skopec M, Issa H, Reed J, et al. The role of geographic bias in knowledge diffusion: a systematic review and narrative synthesis. Res Integr Peer Rev 2020;5:1-14.

58 Kagina BM, Wiysonge CS, Machingaidze S, et al. The use of supplementary immunisation activities to improve uptake of current and future vaccines in low-income and middle-income countries: a systematic review protocol. BMJ Open 2014;4:e004429.

59 Griffiths UK, Hanvoravongchai P, Oliveira-Cruz V. A toolkit for assessing the impacts of measles eradication activities on immunization services and health systems at country level developed for a multi-country study undertaken between July 2009 - July 2010. London School of Hygiene and Tropical Medicine, 2010.

60 World Health Organization (WHO). Who. statement on the sixth meeting of the International health regulations (2005) emergency Committee regarding the coronavirus disease (COVID-19) pandemic, 2021. Available: https://www.who.int/news/item/ 15-01-2021-statement-on-the-sixth-meeting-of-the-internationalhealth-regulations-(2005)-emergency-committee-regarding-thecoronavirus-disease-(covid-19)-pandemic [Accessed Jan 2021].

61 Goodman RA, Buehler JW, Mott JA. Defining field epidemiology: centres for disease control and prevention, 2018. Available: https:// www.cdc.gov/eis/field-epi-manual/chapters/Defining-Field-Epi.html [Accessed Jan 2021].

62 Nelson R. COVID-19 disrupts vaccine delivery. Lancet Infect Dis 2020;20:546.

63 Polio Global Eradication Initiative. Latest on COVID-19, 2020. Available: https://polioeradication.org/wp-content/uploads/2020/08/ GPEI-Newsletter-Week32-2020.pdf [Accessed Mar 2021].

64 Shretta R, Hupert N, Osewe P, et al. Vaccinating the world against COVID-19: getting the delivery right is the greatest challenge. BMJ Glob Health 2021;6:e005273.

65 World Bank Group. The World Bank. Assessing Country Readiness for COVID-19 Vaccines - First Insights from the Assessment Rollout. Washington D.C, 2021.

66 Our World in Data. The decade of the last recorded case of paralytic polio by country, 2017. Available: https://ourworldindata.org/ grapher/the-decade-of-the-last-recorded-case-of-paralytic-polio-bycountry [Accessed Mar 2021].

67 Mangrio NK, Alam MM, Shaikh BT. Is expanded programme on immunization doing enough? viewpoint of health workers and managers in Sindh, Pakistan. J Pak Med Assoc 2008;58:64-7.

68 van Turennout $\mathrm{C}$, Vandelanotte J, van den Akker M, et al. A mass campaign too often? results of a vaccination coverage survey in the Dikgale-Soekmekaar district. S Afr Med J 2003;93:65-8.

69 Verguet S, Jassat W, Bertram MY, et al. Impact of supplementa immunisation activity (Sia) campaigns on health systems: findings from South Africa. J Epidemiol Community Health 2013;67:947-52.

70 Zuber PLF, Yaméogo KR, Yaméogo A, et al. Use of administrative data to estimate mass vaccination campaign coverage, Burkina Faso, 1999. J Infect Dis 2003;187 Suppl 1:S86-90. 